\title{
Apoptosis and Cell Cycle Pathway-focused Genes Expression Analysis in Patients with Different Forms of Thyroid Pathology
}

\author{
Iryna Bilous ${ }^{1 *}$, Larysa Pavlovych ${ }^{1}$, Inna Krynytska ${ }^{2}$, Mariya Marushchak $^{2}$, Aleksandr Kamyshnyi $^{3}$ \\ ${ }^{1}$ HSEEU "Bukovinian State Medical University", Chernivtsi, Ukraine; ${ }^{2}$ l. Horbachevsky Ternopil National Medical University, \\ Ternopil, Ukraine; ${ }^{3}$ Zaporizhzhia State Medical University, Zaporizhzhia, Ukraine
}

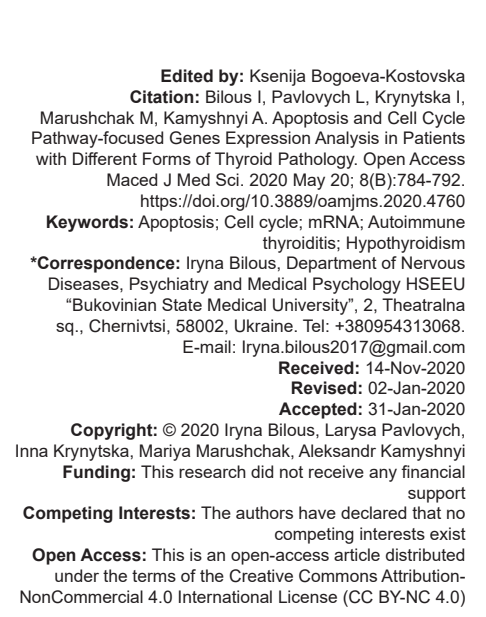

Abstract

BACKGROUND: Thyroid hormones are key regulators of essential cellular processes, including proliferation, differentiation, and finally, apoptosis.

AIM: The aim of the study was to detect changes in the expression of apoptosis and cell cycle pathway-focused genes in patients with different forms of thyroid pathology.

PATIENTS AND METHODS: Thirty-six patients with thyroid pathology were enrolled in the study. We used the pathway-specific real-time PCR array (Neurotrophins and Receptors RT $^{2}$ Profiler PCR Array, QIAGEN, Germany) to identify and verify apoptosis and cell cycle pathway-focused genes expression in patients with post-operative hypothyroidism, hypothyroidism as a result of autoimmune thyroiditis (AIT) and AIT with elevated serum and antithyroglobulin (anti-TG) and anti-thyroid peroxidase (anti-TPO) antibodies

RESULTS: It was shown that patients with elevated serum anti-TG and anti-TPO antibodies and with hypothyroidism resulting from AIT had a significantly lower expression of FAS, TGFB, TP53, and TGFA, while the expression of CD40 was increased. The mRNA levels of BCL2 and BAX decreased in the patients with elevated serum anti-TG and anti-TPO antibodies and increased in the patients with hypothyroidism, resulting from AIT and post-operative hypothyroidism. The patients with hypothyroidism resulting from AIT and post-operative hypothyroidism had significantly lower expression of HSPB1. NF1 expression did not change in all groups of patients.

CONCLUSION: The results of this study demonstrate that AIT and hypothyroidism affect the mRNA-level expression of apoptosis and cell cycle pathway-focused genes in a gene-specific manner and that these changes to gene expression can be responsible for the apoptosis signs and symptoms associated with thyroid pathology.

\section{Introduction}

Thyroid disorders affect approximately $6.6 \%$ of the world population. In the Central, Northern, and Eastern Europe, there is a recorded increasing incidence of such disorders since the Chernobyl nuclear accident in 1986 [1]. The most prevalent autoimmune thyroid disorder, Hashimoto's thyroiditis $(\mathrm{HT})$, results in lymphocytic infiltration of the thyroid gland, often followed by gradual destruction and fibrous replacement of the thyroid parenchymal tissue. Antibodies against thyroperoxidase and thyroglobulin are of immunoglobulin G class, both with high affinity for their respective antigens. Multiple susceptibility genes may be involved in the disease development, some of which are implicated in other autoimmune diseases, while others are specific for thyroid autoimmunity [2].

Thyroid hormones (THs) are key regulators of essential cellular processes, including proliferation, differentiation, and finally, apoptosis [3], involving the interaction of many pro- and anti-apoptotic genes.
A number of cell cycle regulatory proteins modulate programmed cell death. The intrinsic apoptosis pathway involves DNA damage and/or free radical generation; activated nuclear or mitochondrial p53 is an important mediator of such signaling. The extrinsic apoptosis pathway is activated by cell surface factors, for example, tumor necrosis factor- $\alpha$ (TNF- $\alpha)$ and Fas ligand [4].

Transcriptome analysis is an important indicator of the functional activity of cells [5]. THs affect transcription of a number of genes relevant to apoptosis [6], but the studies so far have been inconclusive. The actions of THs can be classified into two main mechanisms: A non-genomic effect initiated at the cell membrane mediating downstream gene expression through the integrin $\alpha v \beta 3$; and transcription initiated by interactions with nuclear $\mathrm{TH}$ receptor proteins followed by binding to $\mathrm{TH}$ response elements of specific downstream genes [7].

We aimed to detect changes in the expression of apoptosis and cell cycle pathway-focused genes in patients with different forms of thyroid pathology. 


\section{Materials and Methods}

Thirty-six patients with thyroid pathology were enrolled in the study. They were divided into three groups: Group 1 included 12 patients with post-operative hypothyroidism; Group 2 included 12 patients with hypothyroidism as a result of autoimmune thyroiditis (AIT); Group 3 included 12 patients with AIT with rising serum and anti-thyroglobulin (anti-TG) and anti-thyroid peroxidase (anti-TPO) antibodies. Control group included 12 healthy individuals, which were recruited randomly, without matching for age or sex.

Blood specimens were collected between 8 and $10 \mathrm{am}$ after an overnight fast. Free triiodothyronine (fT3) (normal range 1.2-3.2 $\mathrm{nmol} / \mathrm{L}$ ), free thyroxine (fT4) (normal range 6.0-13.0 pmol/L for males and 7.0-13.5 pmol/L for females), thyroid-stimulating hormone (TSH) (normal range 0.3-4.0 $\mathrm{mIU} / \mathrm{mL}$ ), antiTPO (normal range $0-30 \mathrm{IU} / \mathrm{mL}$ ), and anti-TG (normal range 0-65 IU $/ \mathrm{mL}$ ) antibodies levels were determined using STAT FAX303/Plus (Awareness Technology Inc., USA).

Hypothyroidism was diagnosed due to the recommendations of the American Association of Clinical Endocrinologists 2012 [8]. The diagnosis of AIT was performed according to circulating antibodies to thyroid antigens (anti-TPO and anti-TG) and reduced echogenicity on thyroid sonogram in a patient with proper clinical features [8].

Patients under the age of 18 or with any malignancy, inflammation associated rheumatic diseases or acute/chronic infection, cases with diabetes mellitus, cases with cardiovascular or cerebrovascular diseases, pregnant women and those with chronic hepatic or renal diseases, those who use any drugs that could interfere with thyroid function were excluded from the study.

\section{Statement of ethics}

All patients provided informed written consent and protocol of research was ethically approved by the HSEEU "Bukovinian State Medical University" and Chernivtsi Regional Endocrinology Center ethics committees.

We used a pathway-specific PCR array (Neurotrophins and Receptors $\mathrm{RT}^{2}$ Profiler PCR Array, QIAGEN, Germany) to identify and verify genes expression in each individual of the studied and control groups. The Human Neurotrophin and Receptors $\mathrm{RT}^{2}$ Profiler PCR Array is designed for expression analysis of 84 genes related to neuronal processes plus five housekeeping genes and three controls. Neurotrophic signaling molecules on this array include NTs and neuropeptides along with their receptors. Genes involved in the normal functions of the neuronal system include neuronal cell growth and differentiation and neuronal regeneration and survival. The array also contains the cytokines and receptors involved in neuronal signaling along with genes involved in the transmission of nerve impulses, genes involved in neuronal apoptosis in response to neurotrophic factors and transcription factors and regulators indicative of the activation pathways downstream of the neuronal system. The expression of these genes was reliably analyzed using real-time PCR.

\section{Experimental procedures}

\section{RNA isolation}

Total RNA was isolated from white blood cells using NucleoZOL (Macherey-Nagel, Germany) according to the manufacturer's instructions. NucleoZOL is designed for the isolation of total RNA (small and large RNA) in single or separate fractions from a variety of sample materials such as cells, tissue, and liquids from human or animal origin. White blood cells were lysed and homogenized in NucleoZOL reagent based on guanidinium thiocyanate and phenol.

\section{cDNA synthesis}

The RNA quality was determined using a spectrophotometer and was reverse transcribed. The concentration and quality of the isolated total RNA were determined on a spectrophotometer NanoDrop (Thermo Scientific ${ }^{\mathrm{TM}}$, USA). For the reverse transcription procedure, using a cDNA conversion $\mathrm{RT}^{2}$ First Strand Kit (QIAGEN, Germany, Cat. no. 330401), RNA samples with the ratio A260/A280 within the range of 1.8-2.2 were selected.

The RT2 HT First Strand Kit procedure comprises two steps: Elimination of genomic DNA contamination and reverse transcription, which enables fast and easy handling of 96 RNA samples simultaneously. After genomic DNA elimination, the RNA sample undergoes reverse transcription with an RT master mix, as well as random hexamers and oligo-dT prime reverse transcription to capture more difficult-to-detect genes.

\section{PCR array}

The cDNA was then used with RTI Profiler PCR Array (QIAGEN, Cat. no. PAHS-031Z) in combination with RTI SYBR ${ }^{\circledR}$ Green qPCR Mastermix (QIAGEN, Cat. no. 330504), following the complete RT2 Profiler PCR Array procedure (www.qiagen.com). Samples were assigned to control and study groups. $C_{T}$ values were normalized based on a/an automatic selection from the full panel of reference genes. 
Any $\mathrm{Ct}$ value $>35$ was considered to be a negative call. The RT2 Profiler PCR Array data analysis software calculates the fold change based on the widely used and agreed upon $\Delta \Delta \mathrm{Ct}$ method. The data analysis web portal calculates fold change/ regulation using delta-delta $\mathrm{C}_{\mathrm{T}}$ method, in which delta $\mathrm{C}_{T}$ is calculated between the gene of interest (GOI) and an average of reference genes (HKG), followed by delta-delta $\mathrm{C}_{\mathrm{T}}$ calculations (delta $\mathrm{C}_{\mathrm{T}}$ [Test Group]-delta $\mathrm{C}_{\mathrm{T}}$ [Control Group]). Fold change is then calculated using $2^{\wedge}$ (-delta-delta $\mathrm{C}_{\mathrm{T}}$ ) formula. These data analysis report was exported from the QIAGEN web portal at GeneGlobe. The software allows to define the best reference genes for normalization. In further analysis, apoptosis and cell cycle pathway-focused genes were selected for this work; a list of these genes is given in Table 1.

Table 1: Apoptosis and cell cycle pathway-focused genes

\begin{tabular}{|c|c|c|c|}
\hline UniGene & RefSeq & Symbol & Description \\
\hline Hs.624291 & NM 004324 & BAX & BCL2-associated $\mathrm{X}$ protein \\
\hline Hs. 150749 & NM_000633 & $\mathrm{BCL} 2$ & B-cell CLL/lymphoma 2 \\
\hline Hs. 472860 & NM_001250 & CD40 & $\begin{array}{l}\text { CD40 molecule, TNF receptor superfamily } \\
\text { member } 5\end{array}$ \\
\hline Hs.667309 & NM 000043 & FAS & Fas (TNF receptor superfamily, member 6 ) \\
\hline Hs.520973 & NM_001540 & HSPB1 & Heat shock $27 \mathrm{kDa}$ protein 1 \\
\hline Hs. 113577 & NM_000267 & NF1 & Neurofibromin 1 \\
\hline Hs. 170009 & NM 003236 & TGFA & Transforming growth factor, alpha \\
\hline Hs. 645227 & $\mathrm{NM}^{-} 000660$ & TGFB1 & Transforming growth factor, beta 1 \\
\hline Hs. 437460 & NM_000546 & TP53 & Tumor protein p53 \\
\hline
\end{tabular}

\section{Statistical analysis of PCR array data}

The RT2 Profiler PCR Array Data Analysis software does not perform any statistical analysis beyond the calculation of $p$-values using a Student's t-test (two-tail distribution and equal variances between the two samples) based on the triplicate $2^{\wedge}(-\Delta \mathrm{CT})$ values for each gene in the experimental group compared to the control group. The microarray quality control published results indicating that a ranked list of genes based on a fold-change and such a $p$-value calculation was sufficient to demonstrate reproducible results across multiple microarrays and PCR arrays, including the RT2 Profiler PCR arrays.

\section{Results}

Gene regulators of apoptosis are divided into anti-apoptotic (BCL2, HSPB1, TGFA); pro-apoptotic (BAX, FAS, NF1, TP 53) and promiscuous (CD40, TGFB1) (Figure 1a-c). The results from RT2 Profiler Apoptosis and cell cycle pathway-focused genes expression analysis indicated that in Group 1 which include patients with post-operative hypothyroidism among anti-apoptotic genes, the expression of BCL2 and TGFA was increased by 3.2 and 4.5 times correspondingly, whereas the HSPB1 was downregulated (11.8-fold) (Table 2 and Figure 2). The expression of pro-apoptotic genes, such as BAX, FAS,
NF1, and TP 53, significantly did not change (Figure 1a). While the expression of promiscuous genes, regulators of apoptosis have changed in different ways. Thus, a decrease in CD40 expression (3.9-fold) was noted, while TGFB1 expression was increased (4.9-fold) (Figure 1a).

In patients with hypothyroidism as a result of AIT (Group 2), the expression of apoptosis regulator genes changed as follows: Among anti-apoptotic genes, BCL2 was upregulated (6,6-fold), on the other hand, TGFA and HSPB1 were downregulated by 46.4 and 11.2 times correspondingly (Table 2). Among proapoptotic genes, the increase in the expressions of BAX (11.6-fold) was observed; in contrast, the expressions of FAS (28.8-fold) and TP53 (66.9-fold) was decreased (Figure 1b). As shown in Table 2, the expression of

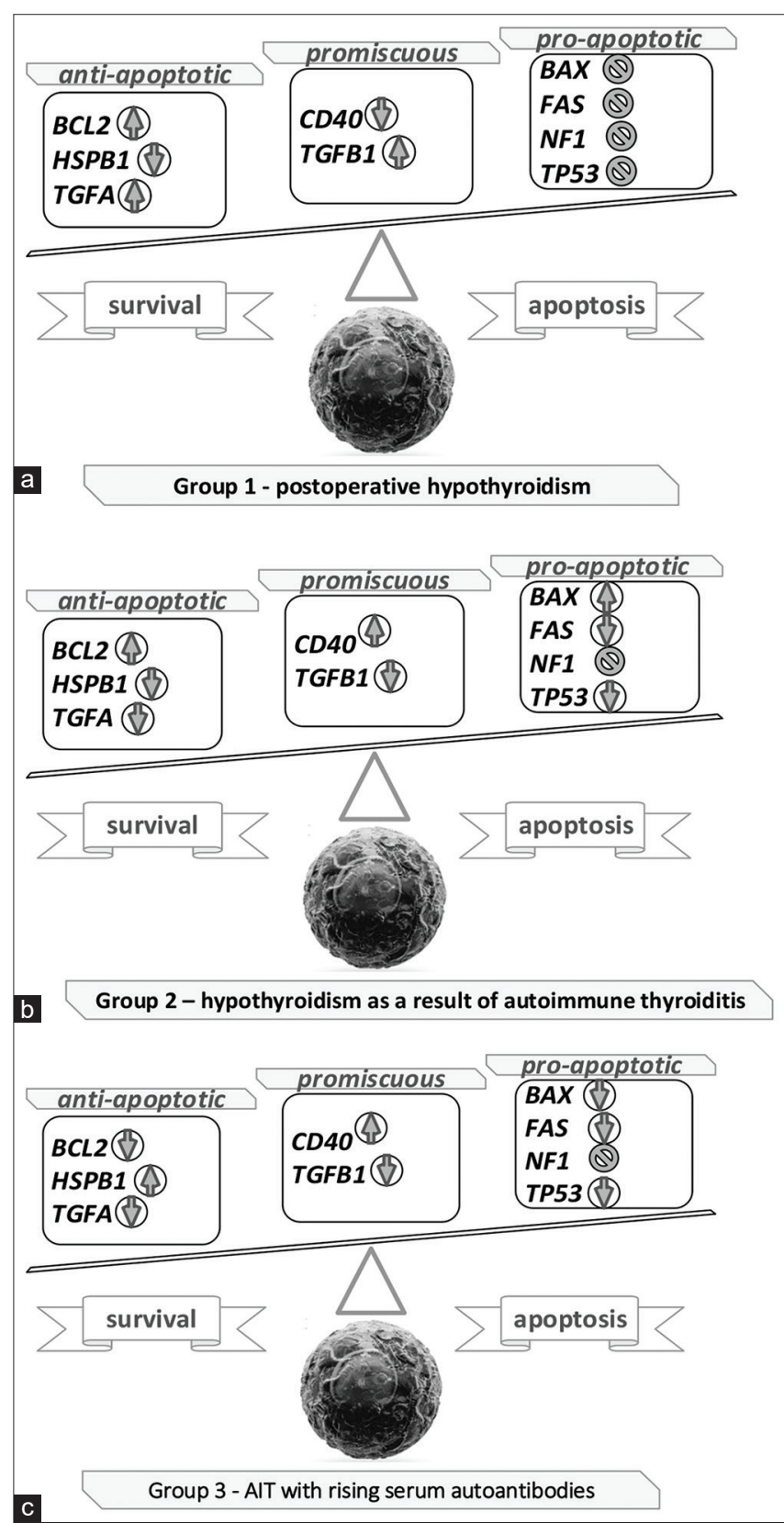

Figure 1: (a-c) Differential expression of mRNA apoptosis and cell cycle pathway-focused genes in patients with thyroid pathology. (4) - upregulated genes, (8) - unchanged genes, (1) - downregulated genes 
Table 2: Differential expression of mRNA apoptosis and cell cycle pathway-focused genes in patients with different thyroid pathology

\begin{tabular}{llll}
\hline Gene symbol & \multicolumn{2}{l}{ Up-down regulation (comparing to the control group) } & \\
\cline { 2 - 4 } & $\begin{array}{l}\text { Patients with post-operative hypothyroidism } \\
\text { (Group } 1)\end{array}$ & $\begin{array}{l}\text { Patients with hypothyroidism as a result of AIT } \\
\text { (Group } 2)\end{array}$ & $\begin{array}{l}\text { Patients with AIT with rising serum anti-TG and anti-TPO autoantibodies } \\
\text { (Group 3) }\end{array}$ \\
\cline { 2 - 4 } & Fold regulation & Fold regulation & Fold regulation \\
\hline BAX & $2.8014(p=0.053441)$ & $11.5792(p=0.001038)$ & $-23.2202(p=0.000154)$ \\
BCL2 & $3.2106(p=0.004666)$ & $6.5893(p=0.033823)$ & $-26.3667(p=0.000804)$ \\
CD40 & $-3.883(p=0.000337)$ & $6.3209(p=0.028077)$ & $9.9592(p=0.044469)$ \\
FAS & $2.6018(p=0.057688)$ & $-28.7709(p=0.000465)$ & $-44.4459(p=0.000178)$ \\
HSPB1 & $-11.8255(p=0.00008)$ & $-11.1827(p=0.000501)$ & $5.9906(p=0.047287)$ \\
NF1 & $-1.0574(p=0.64743)$ & $-1.1018(p=0.372849)$ & $-1.1308(p=0.402653)$ \\
TGFA & $4.4573(p=0.009709)$ & $-46.4155(p=0.003209)$ & $-17.5976(p=0.004579)$ \\
TGFB1 & $4.8663(p=0.004832)$ & $-21.8042(p=0.021417)$ & $-38.514(p=0.000167)$ \\
TP53 & $2.0555(p=0.051796)$ & $-66.8661(p=0.000361)$ & $-29.6641(p=0.000315)$
\end{tabular}

CD 40 was significantly higher in Group 2 (6.3-fold), whereas the expression of TGFB1 was significantly lower in this group (21.8-fold).

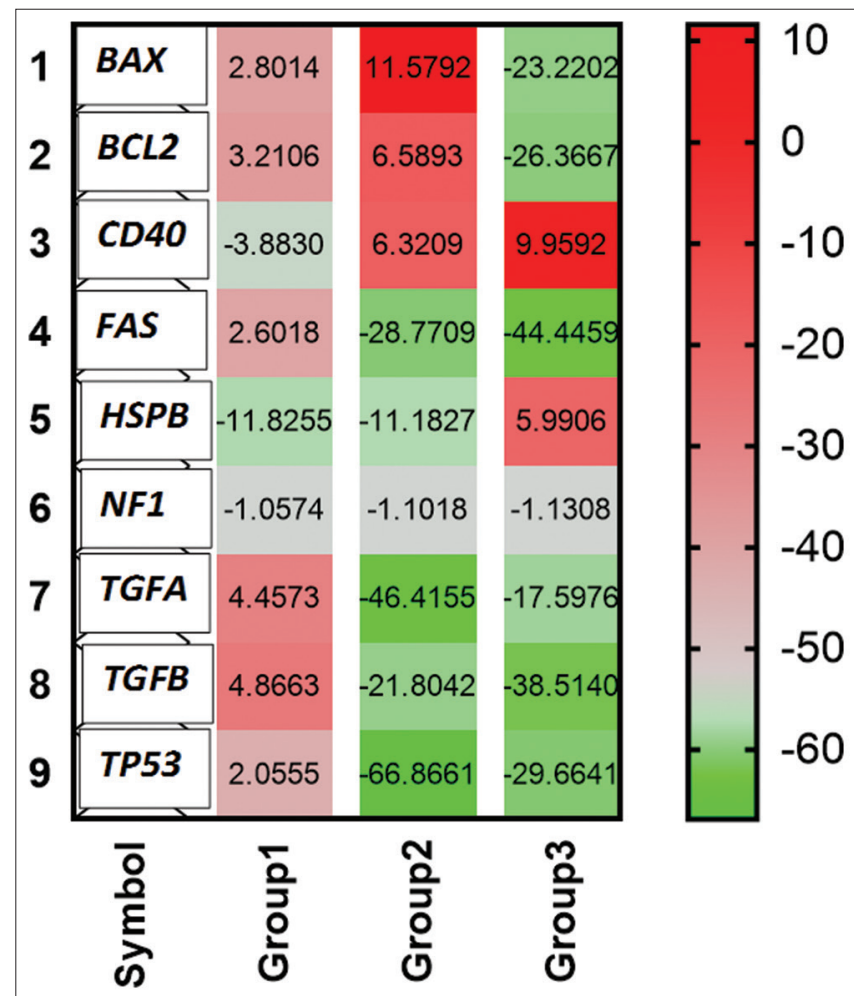

Figure 2: Heat map plot of mRNA apoptosis and cell cycle pathwayfocused genes expression in patients with thyroid pathology

We noted that in Group 3 which includes patients with AIT with rising serum anti-TG and antiTPO autoantibodies that anti-apoptotic genes such as BCL2 and TGFA were downregulated by 26.4 and 17.6 times correspondingly. At the same time, mRNA level of HSPB1 was significantly increased (6.0-fold) (Figure 1c and Figure 2). Reduction in BAX (23.2fold), FAS (44.5-fold), and TP53 (29.7-fold), mRNAs were found in Group 3. The expression of CD40 was markedly increased in Group 3 (10.0-fold), whereas mRNA level of TGFB1 was significantly decreased (38.5-fold).

The $p$ values are calculated based on a Student's t-test of the replicate $2^{\wedge}$ (-Delta CT) values for each gene in the control group and study groups

\section{Discussion}

The B cell lymphoma-2 (BCL-2) family of proteins is key regulators of programmed cell death. They are predominantly localized on the outer membrane of mitochondria, regulating a critical decision point, cytochrome $\mathrm{c}$ release. This protein family consists of both anti-apoptotic (Bcl-2, Bcl-XL) and pro-apoptotic (Bcl-2 associated protein $\mathrm{X}$, Bax; B-cell homologous antagonist/killer, bak) molecules. The survival or death of a cell depends on the balance of BCL2 levels induced through a dynamic process by cellular signaling modulating the expression of proor anti-apoptotic proteins [9]. In our study, BCL2 was significantly suppressed in the group of AIT patients with increased serum autoantibodies, such as anti-TG and anti-TPO, while in the patients with hypothyroidism stemming from AIT and post-operative hypothyroidism, BCL2 expression was elevated.

After a cell receives apoptotic signals, BAX protein migrates from the cytoplasm to the mitochondrial membrane, inducing its damage and subsequent apoptosis. In our study, a decrease in BAX expression was found in AIT patients with elevated serum autoantibodies, such as anti-TG and anti-TPO, while in patients with hypothyroidism as a result of AIT or post-operative hypothyroidism, BAX expression was increased.

Singh et al. evaluated the effect of hypothyroidism on $\mathrm{Bcl}-2$ family gene expression in the developing rat cerebellum. The anti-apoptotic genes $\mathrm{Bcl}-2$ and $\mathrm{Bcl}-\mathrm{XL}$ were downregulated and the proapoptotic gene BAX was expressed at higher levels compared with the euthyroid state. These results suggest that normal levels of TH prevent cerebellar apoptosis, whereas hypothyroidism not only increases the extent but also the duration of apoptosis by downregulating the anti-apoptotic genes and maintaining a high level of the pro-apoptotic gene BAX [4].

A study by Alva-Sanchez et al. examined the expression of specific proteins that control cell proliferation (cycline-D1), cell arrest (p21), DNA damage (p53), or apoptosis (Bax and Bcl2) in the hippocampus of hypothyroid rats treated with the NMDA receptor (NMDAR) blocker MK-801 during the induction 
of hypothyroidism [10]. Hypothyroidism increased the expression of markers of DNA damage, cell arrest, and apoptosis but did not affect the marker of cell proliferation. NMDAR blockade prevented the increase in markers of DNA damage and apoptosis but did not affect cell arrest or cell proliferation. This suggests that hypothyroidism promotes cell death mainly by an excitotoxic effect of glutamate.

Several mechanisms are likely to be involved in determining the progress of an autoimmune thyroid disease toward either hypothyroidism or a clinical syndrome known as HT. The regulation of Fas/FasL/ Bcl-2 expression in HT causes thyrocyte apoptosis, tissue damage, and a gradual reduction in thyrocyte numbers, leading to hypothyroidism. Other authors have shown that THs inhibit apoptosis of early differentiating cerebellar granule neurons through an increase in the levels of $\mathrm{Bcl}-2$ protein. Thus, increased serum Bcl-2 may be linked to accelerated apoptosis. Elevated serum Bcl-2 was reported in euthyroid HT patients in contrast to controls and euthyroids [11].

Cluster of differentiation 40 (CD40), a member of the TNFR superfamily, is associated with multiple autoimmune diseases, including HT. Although the CD40 gene is a general autoimmunity gene, it is unique among autoimmunity genes because it is expressed and functional in many non-immune tissues, where it has been shown to contribute to nonspecific inflammatory responses [12]. We found that patients with postoperative hypothyroidism had significantly lower expression of CD40 compared with the control group. On the other hand, high levels of serum anti-TG and anti-TPO antibodies were associated with increased expression of CD40. These findings are supported by Bilir et al. who also found a significantly higher CD40L level in patients with HT compared to healthy controls. TSH, anti-TG, and anti-TPO levels were higher in the HT group than the healthy control group [13].

Apoptosis features prominently in HT because the extrinsic apoptosis induction pathway is activated by the means of binding FasL (CD95L) with its receptor Fas (CD95). After binding the ligand, Fas combines with adaptive protein, which binds procaspase-8. Activated caspase-8 induces cysteine proteases or caspase-3 complex which selectively affects proteins, either suppressing their activity or activating them, and leads to the destruction of a cell [14]. In our study, FAS was downregulated in patients with hypothyroidism resulting from AIT and in patients with AIT with rising serum autoantibodies. Meanwhile, in a group of patients with post-operative hypothyroidism, the expression of FAS did not change. These results suggest that a high level of serum autoantibodies, such as anti-TG and antiTPO, suppress the expression of FAS.

Bossowski et al. reported a significantly higher expression of apoptotic molecules Fas/FasL on the surface of thyroid cells and elevated expression of pro-apoptotic proteins Fas/FasL in thyroid cells [15]. In addition, in this study, a significantly lower percentage of lymphocytes incoming to the thyroid gland was observed, which demonstrated the expression of these molecules. As a result, follicular cells of the thyroid are destroyed either through the mechanism of apoptosis or because of $\mathrm{T}$ cells activity, finally causing the development of hypothyroidism.

In thyrocytes in the active phase of HT Fas and FasL expression were elevated, but these proteins were also expressed in normal thyrocytes [16]. Nonetheless, their concentration was insufficient to initiate apoptosis. Moreover, the authors suggested that the changes in the distribution of apoptotic markers in thyrocytes can be caused by pro-inflammatory cytokines released by macrophages and Th1 lymphocytes such as IFNG, TNFA, and IL-12. Among others, they are responsible for increased Fas expression on the surface of thyrocytes and elevated concentration of procaspases 8, 10, and 7 ; increased expression of Bid, and to a lesser extent Bcl-XL and Bak, as well as a slightly decreased $\mathrm{Bcl}-2$ levels. This stimulation activates apoptosis in the mechanism of suicide or fratricide, leading to the destruction of follicular cells of the thyroid. Łacka and Maciejewski studied the role of apoptosis in the pathogenesis of AIT. They found increased Fas/FasL expression, caspases, and Bid protein concentrations decreased $\mathrm{Bcl}-2$ concentration, and at the same time, increase of Bcl-2 within intrathyroidal lymphocytes [17]. This stimulates thyrocyte apoptosis and damage to thyroid parenchyma. Apoptotic factor of thyrocytes was shown to correlate with clinical symptoms of HT [15]. We also know that TSH, thyroid-stimulating antibody, and thyroid-stimulating blocking antibody inhibit apoptosis by means of decreasing Fas expression [17]. In contrast, Bona et al. [18] reported a direct correlation between the concentration of anti-TPO antibodies in blood serum and the resistance of $T$ cells to Fasinduced apoptosis in a group of untreated patients.

The HSPB1 gene expresses HSPB1, heat shock protein beta-1 protein (also known as Hsp27, heat shock protein 27). This protein is a member of the heat shock protein family, which helps to protect cells underadverse conditions such as infection, inflammation, exposure to toxins, elevated temperature, injury, and disease [19]. HSPB1 acts as a potent inhibitor of apoptosis signaling [20]. Havasi et al. show that HSPB1 can indirectly inhibit BAX activation/oligomerization and MOMP induction to reduce cytochrome c release from the mitochondria [21]. HSPB1 mutations were associated with progressive degeneration of peripheral nerves in Charcot-Marie-Tooth disease type $2 \mathrm{~F}$ and distal hereditary motor neuropathy [22].

In this study, the expression of HSPB1 was decreased in patients with hypothyroidism resulting from AIT as well as post-operative hypothyroidism. In contrast, HSPB1 was significantly upregulated in a group of patients with rising serum autoantibodies. These results suggest that the high level of serum 
autoantibodies, such as anti-TG and anti-TPO will upregulate the expression of HSPB1.
The neurofibromatosis type I (NF-1) gene encodes neurofibromin - a GTPase-activating

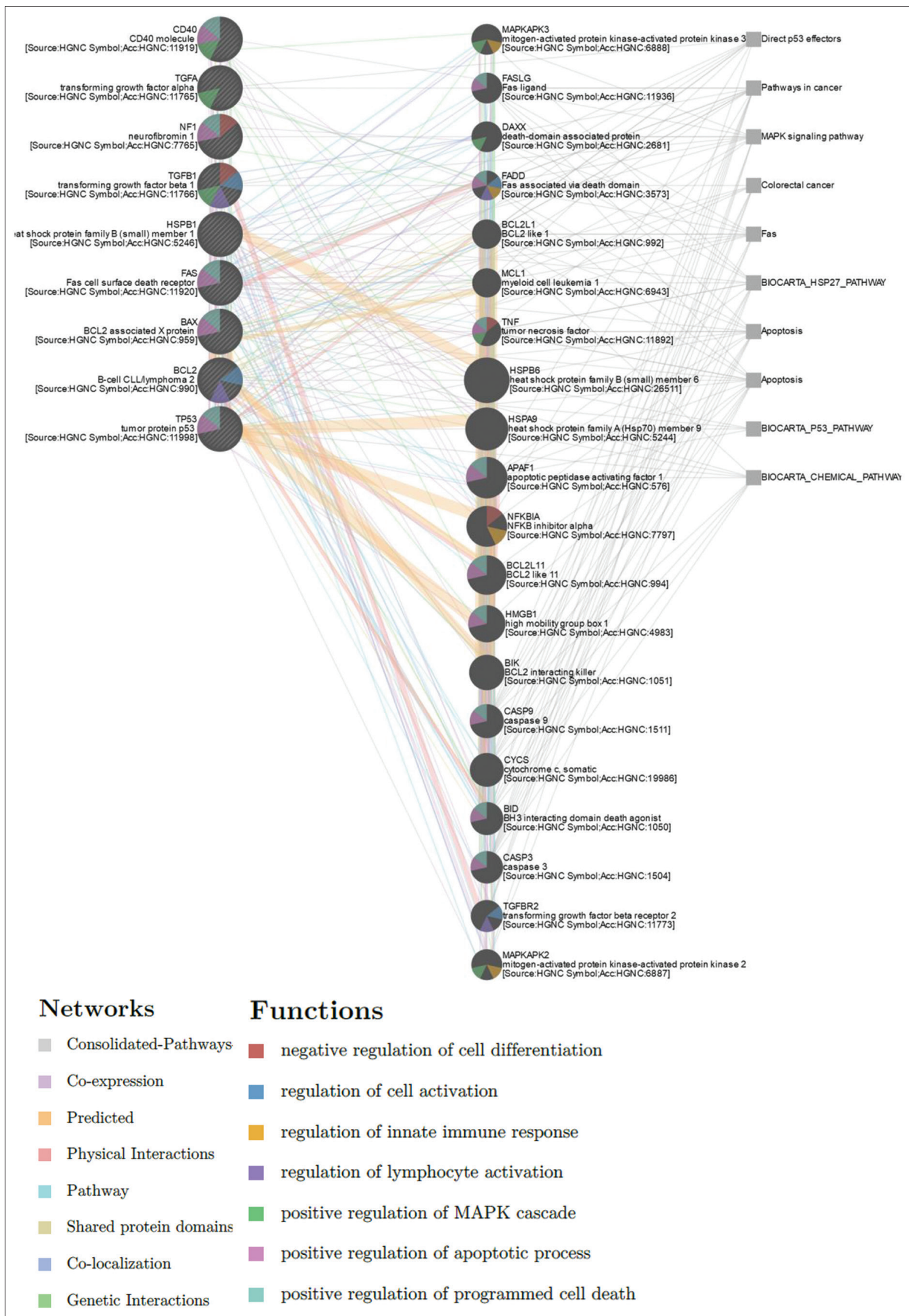

Figure 3: Gene interaction network and functional linkages of apoptosis and cell cycle pathway-focused genes 
protein that downregulates the cellular p21-ras proto-oncogene [23]. It is expressed in neurons, the adrenal medulla, in endothelial and glial cells [24]. The neurofibromin protein is thought to play a key role in autoimmune diseases and NF-1 [25]. We did not detect changes in the transcriptional activity of NF1 gene in patients with primary hypothyroidism and AIT. In the literature, HT is rarely associated with NF-1, and only a few cases have been reported so far. For instance, Nabi described a 30-year-old woman with the concomitant occurrence of goiter and NF-1 [26]. Sasazawa et al. reported a 51-year-old patient with NF1 and HT who suffered a coma as a cause of myxedema [27].

Transforming growth factor $\alpha$ (TGFA) can be produced by a variety of cells, primarily of ectodermal origin, and may interact with the epidermal growth factor (EGF) receptor to induce growth and proliferation responses during cell contact. It is expressed in several tissues, and throughout the entire lifespan of an organism, from embryogenesis to the adult phase. A study of the physiological action of triiodothyronine T3 on the expression of TGFA mRNA in MCF7 cells by inhibition of RNA polymerase II and the MAPK/ERK pathway found that T3 increases the expression of TGFA mRNA in MCF7 cells within $4 \mathrm{~h}$ of treatment [28]. Inhibition of RNA polymerase II modulates the effect of T3 treatment on the expression of TGFA in MCF7 cells. Activation of the MAPK/ERK pathway is not required for T3 to affect the expression of TGFA mRNA. We found that in the patients with elevated serum autoantibodies anti-TG and anti-TPO and the patients with hypothyroidism resulting from AIT, the expression of TGFA decreased. In contrast, TGFA was upregulated in the group of patients with postoperative hypothyroidism.

Transforming growth factor $\beta$ (TGF- $\beta$ ) gene is one of the key genes implicated in genetic predisposition to autoimmune diseases, particularly HT [29]. T allele of $+369 T / C$ SNP, resulting in reduced secretion of TGF- $\beta$, was found to be more frequent in the cases of severe hypothyroidism than mild hypothyroidism [30]. Treatment of hepatic HepG2 cells stably expressing TRs with T3 inhibited their proliferation by arresting them at the transition point between $\mathrm{G} 1$ and $\mathrm{S}$ phases. In addition to other changes, a stimulation of TGF- $\beta$ on the transcription level was observed. The activity of its promoter was increased as much as 8-fold by T3, but this effect was dependent on the presence of active TRs. It was also shown that TGF- $\beta$ neutralizing antibodies and not control antibodies could reverse anti-proliferative effect of T3 in HepG2 cells, suggesting that this is a TGF- $\beta$-mediated mechanism [31]. In this study, TGFB1 was significantly downregulated in the patients with elevated serum autoantibodies anti-TG and anti-TPO, while in the patients with hypothyroidism resulting from AIT the expression of TGFA decreased. In contrast, TGFB1 was upregulated in patients with post-operative hypothyroidism.
The tumor suppressor p53 (TP53) is a short-lived phosphoprotein present in low amounts in the nuclei of normal cells. Activated nuclear or mitochondrial p53 is an important mediator of mitochondrial death signaling. TH may influence the function of p53 by altering its expression, as shown in T47D human breast ductal carcinoma cell line, where p53 levels increased in a T3 concentration-dependent manner [32], or by affecting its post-transcriptional modification, as shown in T4-treated HEK293 and in HeLa cells that do not express TRs. Such treatment promoted p53 phosphorylation by mitogen-activated protein kinase [33]. In this study, reduction in TP53 mRNA was found in the patients with elevated serum autoantibodies anti-TG and anti-TPO, and with hypothyroidism resulting from AIT, while in the patients with post-operative hypothyroidism the expression of TP53 increased.

Therefore, we found that the patients with elevated serum autoantibodies anti-TG and anti-TPO and with hypothyroidism resulting from AIT had a significantly lower expression of FAS, TGFB, TP53, and TGFA, while the expression of CD40 increased. The mRNA levels of BCL2 and BAX decreased in the patients with elevated serum autoantibodies anti-TG and antiTPO and increased in the patients with hypothyroidism resulting from AIT and post-operative hypothyroidism. The patients with hypothyroidism resulting from AIT and post-operative hypothyroidism had significantly lower expression of HSPB1. NF1 expression did not change in all groups of patients.

Using our data on apoptosis and cell cycle pathway-focused genes, we have built gene networks using the GeneMANIA software (http://genemania.org). This allowed us to determine how the candidate genes interact with other genes and generate hypotheses about gene function, analyze gene lists, and prioritize genes for functional assays. As presented in Figure 3, within the gene network that controls the interaction and functional linkages of apoptosis, cell cycle, and cell differentiation regulators, the closest functional linkages were observed between the genes HSPB1 and HSPB6, BCL2 and BCL2L11, TP53 and HMGB1, and FAS and FADD.

\section{Conclusions}

The results of this study demonstrate that AIT and hypothyroidism affect the mRNA-level expression of apoptosis and cell cycle pathway-focused genes in gene-specific manner and that these changes to gene expression can be responsible for the apoptosis signs and symptoms associated with thyroid pathology. 


\section{Data Availability}

The data of this study are available by request.

\section{Authors' Contributions}

IB, LP - concept, design, management of patients, data collection, article draft; IK - responsible for literature search and reference list; $\mathrm{MM}$ - responsible for logical explanation of results, supervision of manuscript; AM - responsible for genotyping, final approval of manuscript.

\section{References}

1. Silva Nde O, Ronsoni MF, Colombo BS, Corrêa CG, Hatanaka SA, Canalli $\mathrm{MH}$, et al. Clinical and laboratory characteristics of patients with thyroid diseases with and without alanine aminotransferase levels above the upper tertile-cross-sectional analytical study. Arch Endocrinol Metab. 2016;60(2):101-7. https://doi.org/10.1590/2359-3997000000066

PMid:26331222

2. Zaletel K, Gaberšček S. Hashimoto's thyroiditis: From genes to the disease. Curr Genomics. 2011;12(8):576-88. PMid:22654557

3. Krashin E, Piekiełko-Witkowska A, Ellis M, Ashur-Fabian O. Thyroid hormones and cancer: A comprehensive review of preclinical and clinical studies. Front Endocrinol (Lausanne). 2019;10:59. https://doi.org/10.3389/fendo.2019.00059 PMid:30814976

4. Singh R, Upadhyay G, Kumar S, Kapoor A, Kumar A, Tiwari M, et al. Hypothyroidism alters the expression of Bcl-2 family genes to induce enhanced apoptosis in the developing cerebellum. J Endocrinol. 2003;176(1):39-46. https://doi.org/10.1677/ joe.0.1760039

PMid:12525248

5. Putilin DA, Kamyshnyi AM. Changes of glut1, mTOR and AMPK1a gene expression in pancreatic lymph node lymphocytes of rats with experimental diabetes mellitus. Med Immunol (Russ). 2016;18(4):339-46. https://doi. org/10.15789/1563-0625-2016-4-339-346

6. Lin HY, Glinsky GV, Mousa SA, Davis PJ. Thyroid hormone and anti-apoptosis in tumor cells. Oncotarget. 2015;6:14735-43. https://doi.org/10.18632/oncotarget.4023 PMid:26041883

7. Liu YC, Yeh CT, Lin KH. Molecular functions of thyroid hormone signaling in regulation of cancer progression and antiapoptosis. Int J Mol Sci. 2019;20:4986. https://doi.org/10.3390/ ijms20204986

PMid:31600974

8. Garber JR, Cobin RH, Gharib H, Hennessey JV, Klein I, Mechanick JI, et al. Clinical practice guidelines for hypothyroidism in adults: Cosponsored by the American association of clinical endocrinologists and the American thyroid association. Endocr Pract. 2012;18:988-1028. https://doi.org/10.4158/ep12280.gl

\section{PMid:23246686}

9. Opferman JT, Kothari A. Anti-apoptotic BCL-2 family members in development. Cell Death Differ. 2018;25:37-45. https://doi. org/10.1038/cdd.2017.170

10. Alva-Sanchez C, Rodriguez A, Villanueva I, Anguiano B, Aceves C Pacheco-Rosado J. The NMDA receptor antagonist MK-801 abolishes the increase in both p53 and Bax/Bcl2 index induced by adult-onset hypothyroidism in rat. Acta Neurobiol Exp (Wars). 2014;74(1):111-7. https://doi.org/10.1016/j.neulet.2009.02.017 PMid:24718050

11. Myśliwiec J, Okota M, Nikołajuk A, Górska M. Soluble Fas, Fas ligand and $\mathrm{Bcl}-2$ in autoimmune thyroid diseases: Relation to humoral immune response markers. Adv Med Sci. 2006;51(1):119-22.

PMid: 17357290

12. Huber AK, Finkelman FD, Li CW, Concepcion E, Smith E, Jacobson $\mathrm{E}$, et al. Genetically driven target tissue overexpression of CD40: A novel mechanism in autoimmune disease. J Immunol. 2012;189:3043-53. https://doi.org/10.4049/ jimmunol.1200311 PMid:22888137

13. Bilir B, Soysal-Atile N, Ekiz-Bilir B, Yilmaz I, Bali I, Altintas N, et al. Evaluation of SCUBE-1 and SCD40L biomarkers in patients with hypothyroidism due to Hashimoto's thyroiditis: A single-blind, controlled clinical study. Eur Rev Med Pharmacol Sci. 2016;20(3):407-13. https://doi.org/10.5222/mmj.2016.156 PMid:26914113

14. Pyzik A, Grywalska E, Matyjaszek-Matuszek B, Roliński J. Immune disorders in Hashimoto's thyroiditis: What do we know so far? J Immunol Res. 2015;2015:979167. https://doi. org/10.1155/2015/979167 PMid:26000316

15. Bossowski A, Czarnocka B, Stasiak-Barmuta A, Bardadin K, Urban M, Dadan J. Analysis of Fas, FasL and Caspase-8 expression in thyroid gland in young patients with immuneandnonimmune thyroid diseases. Endokrynol Pol. 2007;58(4):303-13. https://doi.org/10.1080/08916930701727749 PMid:18058722

16. Stassi G, Todaro M, Bucchieri F, Stoppacciaro A, Farina F, Zummo G, et al. Fas/Fas ligand-driven $T$ cell apoptosis as a consequence of ineffective thyroid immunoprivilege in Hashimoto's thyroiditis. J Immunol. 1999;162(1):263-7. PMid:9886394

17. Łacka K, Maciejewski A. The role of apoptosis in the etiopathogenesis of autoimmune thyroiditis. Pol Merkur Lekarski. 2012;32(188):87-92. PMid:22590910

18. Bona G, Defranco S, Chiocchetti A, Indelicato M, Biava A Difranco $D$, et al. Defective functionof $F$ as in $T$ cells from paediatric patients with autoimmunethyroid diseases. Clin Exp Immunol. 2003;133(3):430-7. https://doi. org/10.1046/j.1365-2249.2003.02221.x PMid:12930371

19. Breed ER, Hilliard CA, Yoseph B, Mittal R, Liang Z, Chen CW et al. The small heat shock protein HSPB1 protects mice from sepsis. Sci Rep. 2018;8(1):12493. https://doi.org/10.1038/ s41598-018-30752-8

PMid:30131526

20. Kanagasabai R, Karthikeyan K, Vedam K, Qien W, Zhu Q, llangovan G. Hsp27 protects adenocarcinoma cells from UV-induced apoptosis by Akt and p21-dependent pathways of survival. Mol Cancer Res. 2010;8(10):1399-412. https://doi. org/10.1158/1541-7786. mcr-10-0181

PMid:20858736

21. Havasi A, Li Z, Wang Z, Martin JL, Botla V, Ruchalski K, 
et al. Hsp27 inhibits Bax activation and apoptosis via a phosphatidylinositol 3-kinase-dependent mechanism. J Biol Chem. 2008;283(18):12305-13. https://doi.org/10.1074/jbc. m801291200

PMid:18299320

22. Carra S, Crippa V, Rusmini $P$, Boncoraglio A, Minoia $M$, Giorgetti E, et al. Alteration of protein folding and degradation in motor neuron diseases: Implications and protective functions of small heat shock proteins. Prog Neurobiol. 2012;97(2):83-100. https://doi.org/10.1016/j.pneurobio.2011.09.009 PMid:21971574

23. Güler S, Yeşil G, Önal H. Endocrinological evaluations of a neurofibromatosis type 1 cohort: Is it necessary to evaluate autoimmune thyroiditis in neurofibromatosis type 1? Balkan Med J. 2017;34(6):522-6. https://doi.org/10.4274/ balkanmedj.2015.1717

PMid:28552839

24. Gutmann DH, Ferner RE, Listernick RH, Korf BR, Wolters PL, Johnson KJ. Neurofibromatosis type 1. Nat Rev Dis Primers. 2017;3:17004. https://doi.org/10.1038/nrdp.2017.4 PMid:28230061

25. NandaA. Autoimmune diseases associated with neurofibromatosis type 1. Pediatr Dermatol. 2008;25(3):392-3. https://doi. org/10.1111/j.1525-1470.2008.00692.x PMid:18577055

26. Nabi J. Neurofibromatosis type 1 associated with Hashimoto's thyroiditis: Coincidence or possible link. Case Rep Neurol Med. 2013;2013:1-4. https://doi.org/10.1155/2013/910656

27. Sasazawa DT, Tsukumo DM, Lalli CA. Myxedema coma in a patient with type 1 neurofibromatosis: Rare association. Arq Bras Endocrinol Metabol. 2013;57(9):743-7. https://doi. org/10.1590/s0004-27302013000900012 PMid:24402022

28. Silva TM, Moretto FC, Sibio MT, Gonçalves BM, Oliveira M,
Olimpio RM, et al. Triiodothyronine (T3) upregulates the expression of proto-oncogene TGFA independent of MAPK/ ERK pathway activation in the human breast adenocarcinoma cell line, MCF7. Arch Endocrinol Metab. 2019;63(2):142-7. https://doi.org/10.20945/2359-3997000000114

PMid:30916164

29. Stanilova SA, Gerenova JB, Miteva LD, Manolova IM. The role of transforming growth factor- $\beta 1$ gene polymorphism and its serum levels in Hashimoto's thyroiditis. Curr Pharm Biotechnol. 2018;19(7):581-9. https://doi.org/10.2174/13892010196661808 02142803

PMid:30070177

30. Yamada H, Watanabe M, Nanba T, Akamizu T, Iwatani Y. The $+869 \mathrm{~T} / \mathrm{C}$ polymorphism in the transforming growth factorbeta1 gene is associated with the severity and intractability of autoimmunethyroid disease. ClinExp Immunol.2008;151(3):37982. https://doi.org/10.1111/j.1365-2249.2007.03575.x PMid:18190611

31. Yen CC, Huang YH, Liao CY, Liao CJ, Cheng WL, Chen WJ, et al. Mediation of the inhibitory effect of thyroid hormone on proliferation of hepatoma cells by transforming growth factorbeta. J Mol Endocrinol. 2006;36(1):9-21. https://doi.org/10.1677/ jme.1.01911 PMid: 16461923

32. Dinda S, Sanchez A, Moudgil V. Estrogen-like effects of thyroid hormone on the regulation of tumor suppressor proteins, p53 and retinoblastoma, in breast cancer cells. Oncogene. 2002;21:761-8. https://doi.org/10.1038/sj.onc.1205136 PMid:11850804

33. Shih A, Lin HY, Davis FB, Davis PJ. Thyroid hormone promotes serine phosphorylation of p53 by mitogen-activated protein kinase. Biochemistry. 2001;40(9):2870-8. https://doi. org/10.1021/bi001978b

PMid:11258898 